\section{One-Legged Railway.}

An Oil City Derrick correspondent describes the elevated one-wheeled, or, as it is more generally known " one-legged railroad," now being constructed by General Stone in the Bradford oil region. It is attracting a good deal of attention, and there is much speculation as to the probable success or failure of the enterprise. A portion of the line between Bradford and Tarport is completed, and one car of peculiar construction has arrived and been placed on the track. The construction of the road is simple, rapid and easy. On the hard ground logs six feet long and from a foot and a half to two feet in diameter are placed at right angles to the line, and from twelve to fifteen feet apart, the distance varying. In these logs vertical sawed posts, fourteen by fifteen and a half inches, are dovetailedand wedged. These verticals vary in height, and by their length the grade of the road is regulated. On the top of these verti. cals the horizontal pieces to which the rails are spiked are laid, with their ends squarely against one another. These sleepers are ten inches wide by fifteen and a halt in thick ness. By a proper arrangement of vertical and horizontal pieces of timber the timbers on which the rails are laid are kept firmly in position, and two wooden rails, three feet and a half below the top of the iron rail and twenty-two inches apart, are spiked to the vertical posts. Across streams and the swampy ground piles are driven. On this one rail a saddle-shaped car is mounted and supported by two wheels, double flanges. The gondola car now mounted on the portion of the road completed is twenty-two feet long, nine feet wide, and weighs over seven thousand pounds. The car is
a double decker, there being room for freight in the body of the car, and on each side of the saddle. Twenty-two inches below a plane tangent to the upper wheels, at the lowest point of their circumference, four smaller wheels are placed in a horizontal position, and in the same plane, their circumferences being twenty-two inches apart. These run against the wooden guide rails, and keep the car in position. The wheels are attached to standards connected with the iron framework of the car.

\section{Dental Caries.}

The general prevalence of dental caries is chiefly owing to food remaining on and between the teeth after mealsfrom breakfast time till the following morning-when, according to custom, the teeth are brushed; brushed, but probably not cleaned, as the brush is more of ten used to polish the surface merely than to assist in removing what has accumulated between them. Experiments have been referred to that prove the solvent action of weak acids on the teeth; and I think it will be conceded without proof that, were portions of our ordinary food, mixed and moistened as in mastication, kept during the night at the high temperature of the mouth, the compound would be sour. It follows that dental caries must continue to prevail as now, while it is the custom to allow the food to remain in contact with the teeth all night.

The following observations show the dependence of caries on food remaining in contact with the teeth. When the teeth are wide apart food is not retained, and they gen erally remain free from caries. The lower front teeth are seldom attacked by caries when, as is generally the case, the spaces between are closed to the entrance of food by tartar. The backs of all the teeth, upper and lower, being kept free from food by the tongue, are seldom affected by caries. Lodgment of tood takes place between the bicuspids, between the molars, in the depressions on the masticating surface of these teeth, and on the buccal walls of these molars, and these are the chief seats of caries. While mastication is performed by the molars and bicuspids, the upper front teeth remain free from food and from caries; but, when they themselves are made to do the work of lost or diseased molars, and the food gets between them, caries is certain to follow before long. Further proof cannot be required that, if no food remained in contact with the teeth after eating, they would be free from caries, unless acted on by acidity from other sources. The only indications, therefore, for the prevention of dental caries are the neutralization of acid applied to the teeth and the removal of food before it has become acid. The food should be removed after
every meal, and all who have not the opportunity of doing so should not fail to remove it every night at bedtime by rinsing, as the brush cannot be trusted to remove the food from between the teeth._British Medical Journal.

\section{Ancient American Clifr and Cave Dwellings.}

There have been just added to the South Kensington $\mathrm{Mu}$ seum, London, six models (the gift of the United States Gov ernment), illustrating the cliff houses, cave dwellings, and lowland settlements met with through the district where the States of Utah, Colorado, Arizona, and New Mexico join. They are reduced to different scales, the cave dwellings being of smaller scale than the lowland dwellings, since with the former the surroundings are given, while with the latter they are not. The district, which may be called that of the San Juan basin, was surveyed in 1875, and last year some attention was paid to the ruins of ancient dwellings that had been previously noticed. The area examined was 6,000 square miles. The general aspect of the country is that of a semi-desert. Yet there is a bountiful evidence that at one time it supported a numerous population; there is scarcely a square mile in the whole 6,000 examined that would not furnish evidence of occupation by a race totally distinct from furnish evidence of occupation by a race totally distinct from
the nomadic savages who hold it now, and in every way su- perior to them. The ruins of the region are those of stone \begin{tabular}{l|c} 
structures, but the remains are not so perfect as to show to & I give one fourth day each week to composition exercise \\
what extent wood and adobe were used. The only known & The pupils are provided with paper and pencil, several sub-
\end{tabular} traces of the people besides their dwellings are flint and stone jects are placed upon the blackboard, and every pupil reimplements, tied bundles of sticks, fragments of matting, quired to write all he can on one subject. The subjects are pottery, and pictures cut into the walls. A number of burial selected so that all pupils are able to write. The follewing places were noted, but of the graves examined few yielded were used last week: Maple sugar-making, ghosts, telling further evidences of occupation than small quantities of stories, faces, domestic animals, rats, peanuts, observations charcoal and bits of painted pottery. As regards the build- in a railroad car. During this exercise the strictest order is ings, the parallelogram and the circles are the predominant observed. Pupils that experience difficulty write their forms. A greater part of the ordinary structures are square subjects, and then are aided by the teacher, who is constantor rectangular; while attached to each group, and sometimes ly among them. He does not write, however, but suggest without indications of contiguous buildings, are the circular what may be said on the several subjects, and aids them to uins frequently resembling towers. The models, which are form the first sentence. The writing continues just one colored, give a good idea of the structures.- Lomden Building Neros.

\section{CURIOUS BLOOD DISRS.} BY JOHN MICHELS.

In the summer of 1877 , on a visit to the London establishment of Messis. R. \& J. Beck, I purchased a slide that was ffered to me, as a recent addition to their cabinet of microcopical objects for sale. It was represented as a specimen fllows: Blood.—Congo Snake.-Amphiuma Meaus.-R. \& Beck, 31 Cornhill, E.C.

As it is a most interesting specimen, I offer in Fig. 1 ketch I have made by the camera lucida, as a part of it appears magnified by my inch objective and B eye piece, en 310 diameters.

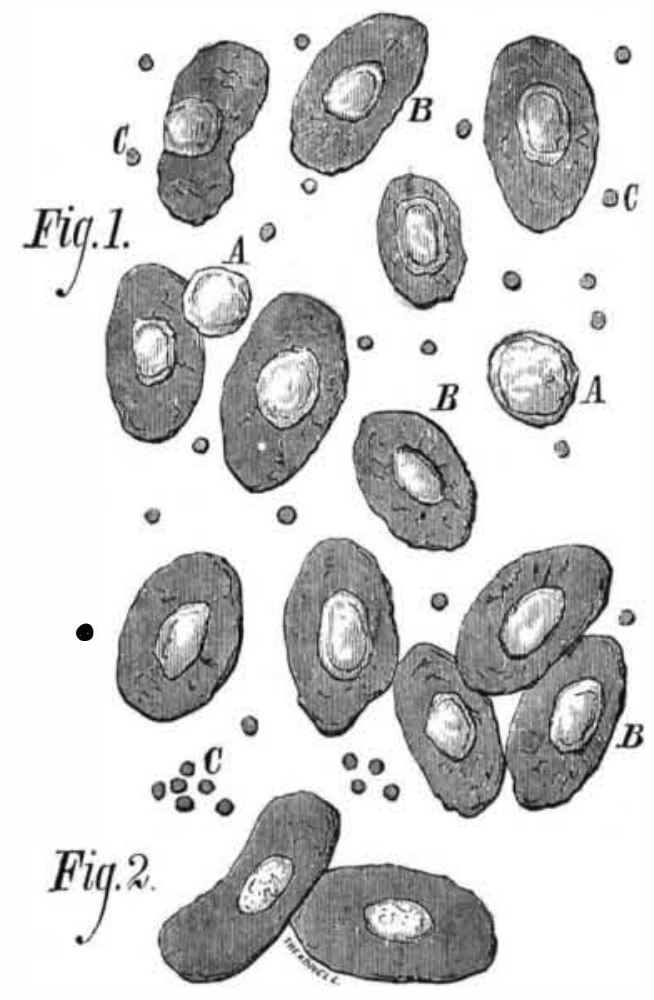

Had the preparation been offered by a less reputable house I should have considered the description on the label an error, as I am not acquainted with a Congo snake, with the above name, and the only "Amphiuma" I know of is a genus of batrachian reptile met with in the lakes and stagnant water
of North America.

As an animal similar in form to a water newt could not be mistaken for a snake, a difficulty is presented, the explanation of which it is not in my power to offer. The red corpustinguished by the unassisted vision, and in their oval form are characteristic of those met with in reptiles.

At letter A will be noticed the white corpuscles, which are smaller in size and circular in form, and thus readily dis tinguished from the red corpuscles, marked B. T'he small
circles are to represent human blood disks similarly enlarged; these are introduced for comparison of size only.

Large as these red corpuseles appear, I find they are yet smaller in size than those met with in another reptile called "menobranchus lateralis," one of the salamander family found in Lake Ontario. This amphibious animal is remarkable from being furnished with both lungs and gills, which permits it to live either on land or in water with equal com fort to itself.

Fig. 2 is a copy of a drawing of the blood disks of the "menobranchus lateralis," enlarged 300 diameters.

A comparison between the illustrations, Figs. 1 and 2, at once shows that, although the red corpuscles of the "am phiuma" are magnified 10 diameters in excess of those of "menobranchus," still the former is the smaller of the two th specimens, thus the "menobranchus lateralis" must still
carry off the palm of having the largest blood disks yet discarry off
covered.

\section{A New Theory of the Nature of Water.} form the first sentence. The writing continues just on
hour, when compositions are folded, superscribed, numbered, and handed to the teacher. The pupils then receive compositions of the previous week, and are required to correct the errors noted on the outside. Fifteen minutes are given, of mistakes which the pupils failed to rectify. This is done by placing the words and sentences on the board, and calling upon different members of the school for correction.
The facility with which young pupils write after a few months' practice is surprising; and while it proves a profitable exercise, it is no less agreeable to the scholars. $-N$. $E$. Journal of Education.

\section{Dyeing Felt Hats.}

The following is a recipe for producing a good black, and giving brightness to the felt. The quantities named are for dyeing $100 \mathrm{hats}$ at one operation. Into a copper containing 55 gallons of boiling water put $9 \mathrm{lbs}$. of liquid extract of $\log$ wood at $30^{\circ}, 4 \frac{1}{2} \mathrm{lbs}$. of crushed brown cashoo, $4 \frac{1}{2} \mathrm{lbs}$. sandal wood in powder, and $2 \frac{1}{4}$ soda crystals. Enclose the whole in a linen bag or wicker basket, so that they do not settle at the bottom of the copper. When the ingredients are dis solved, put the hats in, and allow them to boilgently for two hours; then take them out, and let them get quite cold Now add to the bath $3 \frac{1}{2}$ ozs. of chromate of potash, and 9 ozs. of sulphate of copper; cool the bath by the addition of several pailfuls of water, then again put in the hats, and al low them to simmer for an hour. Again take them out, le them get cold, andafteradding to the bath $2 \frac{1}{4} \mathrm{lbs}$. of sulphate of iron, put the hats in, and let them gently boil for an hour. Should the hats have a rather reddish appearance, add to the bath another $2 \frac{1}{2} \mathrm{lbs}$. of soda crystals. After these operation the hats must be piled up, and covered with a thick cloth for a day; then subject them to a vigorous washing, and eliminate the copper, using muriatic acid rather than sulphuric acid, as the latter draws out the dye. When the copper is thus eliminated, pass the hats into cold water, in orde to free them from the acid. For the final operation, prepare a bath of Panama wood, just simmering, and in this place the hats for half-an hour. This bath sets the color, and gives brightness to the felt. Upon taking them out, if they are soft hats, the water must be drained out of them by pressure.

Observations.-By this procedure a very clear and very bright black is obtained. In order to produce a violet-black the cashoo must be substituted by the same weight of archil a blue-black is obtained by leaving out the cashoo and sandal wood, and replacing them by $4 \frac{1}{2}$ lbs. of archil; for the burnshing the sulphate of iron must be suppressed, and replaced mmediately by $1 \mathrm{lb}$. 2 ozs. of sulphate of copper; if a green ish-black tint or kind of dark bronze is desired, the sandal wood must be substituted by $4 \frac{1}{2} \mathrm{lbs}$. of liquid extract of Cuba yellow wood at $30^{\circ}$. French Hatter.

\section{Astronomical Notes.}

BY BERLIN H. WRIGHT.

Penn Yan, N. Y., Saturday, January 12, 1878.

The following calculations are adapted to the latitude of New York city, and are expressed in true or clock time, being for the date given in the caption when not otherwise stated.

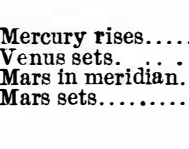

$$
\text { Planets. }
$$

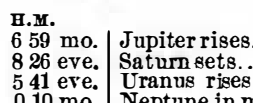
H.M.
709 mo.
919 eve.
750 eve.
643 eve.

\section{Sirius rises........
Procyon rise
Regulus rise

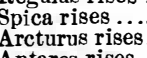 \\ Antares rises..........................}

FIRST MAGNITUDE STARS.

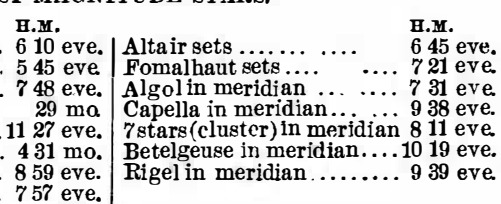

Mercury rises $24 \mathrm{~m}$. before the sun, and $2 \frac{1}{2}^{\circ}$ north of the sunrise point. He is now retrograding. Venus is nearly in the sun's path. She is brightest January 16. Mars is a litte north of the ecliptic, and $\frac{7}{8}$ of his illuminated disc is visible. Jupiter commences to be morning star January 5, and will so continue until April 25. He rises $14 \mathrm{~h}$. before the un, and nearly at the same point. Saturn is $3^{\circ}$ south of the ecliptic. He is near the moon January 8,5 h. 40 m. evening, M. Maiche in Les Mondes propounds the theory reached being $4^{\circ} 19^{\prime}$ south. Uranus is still quite near Regulus, being after numerous experiments that water is simply hydrogen nearly $1^{\circ}$ northeast of the star. The wonderful variable star phus electricity, or oxygen minus electricity; or, in other Algol will decline from the $2 \mathrm{~d}$ to the 4 th magnitude between words, that normal electrified hydrogen constitutes water, January $13,0 \mathrm{~h} .33 \mathrm{~m}$. morning, and $3 \mathrm{~h} .57 \mathrm{~m}$. morning; that normal diselectrified oxygen produces the same; also between January $16,9 \mathrm{~h} .22 \mathrm{~m}$. evening, and $12 \mathrm{~h} .46 \mathrm{~m}$ differing only in degree of electrification. 